\title{
Country Risk on the Bank Borrowing Cost Dispersion Within the Euro Area during the Financial and Debt Crises
}

\author{
George Michalopoulos ${ }^{1}$, Konstantinos Tsermenidis ${ }^{2}$
}

\begin{abstract}
:
The purpose of this study is to evaluate the impact of the country risk factors on the dispersion of the cost of bank borrowing within the euro area, during the period of the global financial and Eurozone debt crises.
\end{abstract}

The main aim is to empirically evaluate the degree to which the cost of borrowing differentials of euro area countries can be explained by changing dispersion in country risk (measured by government bond spreads).

The results using rolling estimations suggest that the impacts of bond yield spreads are not such a significant determinant of the observed dispersion of the cost of borrowing, a dispersion that has been worsen after the outbreak of the global financial crisis and the subsequent euro area debt crisis.

Even in the cases where a significant association is found for some countries, it seems that it is weakening as we move further away from the beginning of the turbulent periods.

Keywords: Country risk, cost dispersion, financial and debt crisis.

JEL Classification codes: E4, G21, E43, F330, F360.

\footnotetext{
${ }^{1}$ Associate Professor, Dept of Accounting \& Finance, University of Macedonia, Greece, gmich@uom.gr

${ }^{2}$ Ph.D. Candidate, Dept of Accounting \& Finance, Univ. of Macedonia, Greece, tsermeni@uom.edu.gr
} 


\section{Introduction}

Barriers to financial integration, country specific economic conditions and structural differences in the eurozone members banking markets produce systematic crosscountry differences in the bank lending interest rates. It is widely agreed in the relevant empirical literature, that the law of one price within the euro area banking markets has never been accomplished, while the recent financial and debt crises had a negative impact in the interest rate convergence process. The main explanation for the cross-country differences in the cost of bank borrowing, is often based on differences in country risk, and more specifically on different levels of sovereign risk.

Sovereign bond yields affect bank lending rates, mainly, via three channels: a) through the pricing channel, since government bond yields acts as a benchmark for the interest rate setting in the banking system; b) through the balance-sheet effect, since bank capital gains or losses in their bond portfolio induce fluctuations in the supply of credit and hence in interest rates; finally, c) through the liquidity channel, since a loss in bonds value reduces the bank's ability to draw funds from the money market using bonds as collateral (Neri, 2013).

The purpose of this study is to evaluate the impact of the country specific risk factors as measured by the government bond yield spreads, on the dispersion of the cost of borrowing within the Euro area. To this end, we estimate an empirical model in which each country's spread in the cost of bank borrowing is explained by with the country's government bond yield spread, inflation rate spread and growth rate spread, all spreads calculated by taking the German levels as a benchmark. We use the recently produced indicators of the cost of borrowing of non-financial institutions and households for the long term and the short-term borrowing (ECB 2013). We estimate the model for eight different euro area members separately, namely Belgium, France, Netherlands, Ireland, Italy, Greece, Portugal and Spain. Finally, we apply a rolling version of the same estimator using an estimation window of four years, in order to evaluate the evolution of the relationship between the cost of borrowing and its determinants.

The key conclusion reached here is that both the 2007-08 crisis and the euro area debt crisis that followed have caused significant divergence in the members' cost of borrowing differentials. However, this development can be only partially attributed to the country specific risk, as measured by the government bond yield spreads. This conclusion is apparent both in the estimation results for each individual country for the whole period, and in the evaluation of the evolution of the underlined relationship through time. More specifically, it is shown that the bond yield spreads is significant determinant of the cost of borrowing differentials for only a few subperiods. It seems that in most cases, a significant relationship between bond yield spreads and the cost of borrowing differentials appears only during the initial phases of the crises, while its importance fades away immediately afterwards. 


\section{Literature review}

Integration of the financial markets is an important ingredient of a well-functioning monetary union in EU. Integration can be perceived as the gradual elimination of all factors that work against the prevalence of the law of one price and are related to country specific characteristics. These characteristics might be financial product heterogeneity, structural differences in financial institutions and divergent economic conditions ((Allegret et al., 2016; Boldeanu and Tache, 2016).

According to the relevant literature, the convergence process of the bank lending interest rates, although apparent, had been relatively slow during the pre-2007-08 crisis period (Cabral et al., 2002; Kleimeier et al., 2003; Vajanne, 2007). Moreover, a process of financial fragmentation has been under way during the post-2007 period, as a result of the divergent financial conditions that prevailed within the euro area (ECB, 2013). Retail banking markets seem to be less integrated compared to other financial markets as noted in Cabral et al. (2002). Affinito et al. (2006) point out the significance of the existing market segmentation when examining the Italian banking market. On the other hand, Vajanne (2006) provides evidence of an ongoing integration process. Finally, several more recent studies focus on examining the cross-country differences in the pass-through processes of monetary policy rates on retail banking rates (Blot et al., 2012; Illes et al., 2013; Paries et al., 2014). These studies find that a less effective pass-through mechanism is observed since the 20079 financial crisis. More specifically, they show that the financial turmoil has made the interest rate pass-through in the eurozone less complete and more heterogeneous across members. Such heterogeneity is attributed to the divergent economic conditions and structural differences in individual countries that were aggravated with the financial crisis (Duguleana and Duguleana, 2016; Thalassinos et al., 2015a; 2015b; Chronis and Zombanakis, 2016).

In addition, empirical studies that evaluate interest rate convergence process by using the 'beta' and 'sigma' convergence indicators reach a similar conclusion: The 'beta' and 'sigma' convergence processes, although slow, were at work during the pre-crisis period, but they were disrupted during the period that followed the 2007-9 crisis. Moreover, several recent studies also highlight the role of the Eurozone sovereign debt crisis, by showing the effects of diverging sovereign bond yields and country specific structural problems of banks on the divergence of the banking market interest rates and the increased segmentation (Neri, 2013; Acharya $\mathrm{kal}$ Steffen, 2013; Gennaioli et al., 2014; Becker Kal Ivashina, 2014a; 2014b).

In this study, we aim at examining whether the individual country risk, as measured by the government bond spreads, and specific country macroeconomic conditions are significant contributors to the dispersion of the cost of bank borrowing within the euro area. By doing so, we search for an explanation for the observed weakening of the banking market convergence process during the recent period of financial turbulence. 
Neri (2013), among others, examines the impact of the sovereign risk on the cost of borrowing, in several euro area countries. His main finding is that the sovereign crisis has caused a significant impact on the cost of borrowing through the effect of the sovereign spreads on interest rates for peripheral countries such as Greece, Italy, Portugal and Spain.

However, he finds no significant impact of the bond spreads on interest rates for the other countries. He uses an ARDL model and SUR methodology to evaluate the relationship between bond spreads and banking market interest rates. Building on this study, we attempt to evaluate the effects of the sovereign spreads on the cost of bank borrowing by controlling for the impact of additional explanatory variables such as of growth and inflation. Cross country differences in inflation and growth rates indicate asynchronous business cycles, which might be an additional factor explaining cost of borrowing dispersion. By controlling for this, we can better isolate the effects of country risk, as depicted on the government bonds yields spreads.

\section{Methodology}

As mentioned above, our aim is to empirically evaluate the impact of country risk and country specific economic conditions on the dispersion of the cost of bank borrowing within the euro area. For this purpose, we will assume that for each country, the cost of borrowing differential is determined as below:

$$
R_{i t}=\alpha+\beta B_{i t}+\gamma{\frac{d Y}{Y_{i t}}}_{i t} \delta{\frac{d P}{P_{i t}}}_{i t}
$$

where:

$R_{i t}$ denotes country's $i$ cost of borrowing differential vis-a-vis the cost of borrowing of Germany for month $t$;

$B$ denotes country's $i$ spread of government bond yield vis-a-vis Germany;

$d Y / Y$ denotes the annual GDP growth rate differential vis-a-vis Germany;

$d P / P$ denotes the annual inflation rate differential vis-a-vis Germany.

Since our series might suffer from high persistence, cyclical movements, common factor effects and linear or stochastic trends, we first transform the series in order to minimize such effects and make our analysis more robust. To this end, we employ the Hodrick Prescott high-pass filter to separate a time series into trend and cyclical components. The trend component may contain a deterministic or a stochastic trend and it can be a non-stationary process, while the cyclical component is considered to be a random stationary process.

Hodrick and Prescott (1997) motivated the HP filter as a trend-removal technique that could be applied to data that came from a wide class of data-generating processes. In their view, the technique specified a trend in the data and the data was filtered by removing the trend. The smoothness of the trend depends on the 
parameter $\lambda$. The trend becomes smoother as $\lambda$ tends to infinity, while Hodrick and Prescott recommended setting $\lambda$ to 1,600 for quarterly data. The smoothing parameter determines the periods of the stochastic cycles that drive the stationary cyclical component. Since here we employ monthly data, we use a smoothing parameter of 129,600 as suggested by the Ravn-Uhlig rule.

We first estimate our model using the Generalized Method of Moments estimator on a system of simultaneous equations. The main reasons we follow this approach, is the problems of endogeneity of the variables employed, the existence of common factors and the complex relations that might appear within the variables. It should be noted that, we apply the generalized version of the method of moments, as we make use of several instruments (and hence of moment conditions) that is greater than the number of the variables in the model.

If we had estimated a single equation for the cost of borrowing spread and used the explanatory variables as instruments, our estimator would be the two-stage least squares estimator; however, the main interest here would be on the treatment of the endogenous covariates and how the moment conditions could be sketched so as the estimation is as valid as possible. In order to construct a more efficient estimator, we need to enrich our econometric model with additional equations that better describe the mechanism that drives the series of interest. This way, we can isolate the impact of the country risk, from the impact of the rest variables on the cost of borrowing differentials. Thus, we estimate the following system of equations:

$$
\begin{aligned}
& R_{i t}=\alpha+\beta B_{i t}+\gamma \frac{d Y}{Y}_{i t}+\delta{\frac{d P}{P_{i t}}}_{i t}+\varepsilon_{1 \mathrm{it}} \\
& B_{i t}=\zeta \frac{d Y}{Y_{i t}}+\eta{\frac{d P}{P_{i t}}}_{i t}+\varepsilon_{2 \mathrm{it}}
\end{aligned}
$$

Focusing on the joint estimation of all the parameters of the system, we apply the well-known three-stage least-squares (3SLS) estimator of Zellner and Theil (1962). If we are willing to specify the complete system of structural equations, then assuming our model is correctly specified, by estimating all the equations jointly, we can obtain estimates that are more efficient than equation-by-equation 2SLS.

In the system of equations above, we can see that the variable of cost of borrowing differentials is related to the bond yield spreads, growth and inflation, while in the second equation can be seen that bond yields are associated with growth and inflation. We treat the cost of borrowing differentials and bond yield spreads as endogenous variables, as we assume that the shocks in both equations are not independent from each other. A random positive shock in the second equation, will make bond yields higher than otherwise would be. This way, cost of borrowing in the first equation will also be affected by the change in bond yields as well as by the correlation between the shocks in both equations. 
A defining characteristic of the 3-stage least squares, is that it uses the same set of instruments for all equations of the system. This way, we are using moment conditions based on exogeneity assumptions on the variables of growth and inflation. In order to raise the number of instruments we are using, we will also employ the lagged values of growth and inflation as additional instruments. The three steps of the procedure include first to develop instrumented values for all endogenous variables as provided by regressing each endogenous variable (cost of borrowing and bond yields) on the exogenous variables in the system.

The second step obtains a consistent estimate for the covariance matrix of the disturbances based on the covariance matrix of the residuals, while in the third step we perform an estimation based on the covariance matrix obtained from the second step, using the instruments provided. As we want to control for potential heteroskedastisity and autocorrelation, we use a weight matrix that assumes both heteroskedastisity and cross-equation dependence. So, the weight matrix to be computed from the first step parameter estimates, will be based on a Bartlett kernel with optimal number of lags chosen by the Newey and West's (1994) automatic lagselection algorithm, providing the well-known Newey-West standard errors. This way, the standard errors will be consistent in case heteroskedastisity and autocorrelation are present.

In this study, we mainly focus on the results concerning the parameter estimates on the bond yields from the first equation, rather than reporting all coefficients from both equations. We constructed a system of equations based on assumptions on the structure of the relations, in order to obtain more efficient estimates. Interest rates are likely to be affected by the country risk as measured by the spreads of the bond yields, as well as by growth and inflation, which capture characteristics of the business cycle, the effects of real interest rates on nominal and other economic conditions of individual countries.

The second equation describes the mechanism according to which the bond yields are affected by growth and inflation. In this way, we can better isolate the effect of the bond yields on the cost of borrowing, while growth and inflation can have a separate immediate effect on the cost of borrowing (second equation) and at the same time can affect the cost of borrowing through their impact on the bond yields (third equation).

Moreover, the use of growth and inflation as instruments in both equations, is made under the assumption that these variables are exogenous. While this assumption might not always hold, we can state that the cost of borrowing and bond yields do not have such an immediate impact on inflation and growth. Moreover, the use of growth and inflation and their lagged values as instruments, may be justified by the fact that in most cases (countries), the correlation of growth and inflation with bond yields is much stronger than the correlation of these variables with the cost of borrowing. Finally, we use the Hansen's (1982) J test of over-identifying 
restrictions, in order to check the validity of the instruments used.

As mentioned earlier, Neri (2013) used an ARDL-SUR methodology to evaluate the relationship between sovereign risk and interest rates. Here, we are mainly interested in determining whether the impact of sovereign risk on the cost of borrowing, could be mainly due to the dispersion of the economic conditions of the Euro area countries, instead of the sovereign risk itself. Controlling for these factors, might give a better insight for the actual effect of sovereign risk on lending rates.

Moreover, we apply a rolling estimation of the model to have a better insight on the evolution of the impact of sovereign risk on the cost of borrowing. This rolling estimation is applied to the system estimator. We firstly estimated the parameters of the model, using the whole period of our sample and obtained results for each individual country. These results can be considered as static ones, as the coefficients are based on a unique sample and the conclusions that can be drawn refer to the whole period.

On the other hand, using the rolling version of our estimator, we can obtain a series of parameter estimates together with their robust standard errors described above. This way, we can observe the evolution of the relation between the cost of borrowing and the bond yields and whether this relation was affected by the financial and debt crisis. Moreover, with these estimated series, we can be able to observe potential trends in the process of convergence (or divergence) of the cost of borrowing in individual countries. The rolling window will have a size of 48 months, meaning that each individual observation of the series of coefficients estimated, is based on a period of 4 years, starting from January of 2003 and finishing on June of 2015. This way, the first sample will be from January of 2003 until December of 2006 and the last estimates will be based on the period from July of 2011 until June of 2015.

We estimated the same model using different versions and variations, in order to check whether the potential existence of unit roots, high persistence of shocks and different specifications concerning the use of instruments and lagged dependent variables could alter our results significantly. We find however, that the results concerning the impact of the bond yields' spreads do not appear to be significantly different in the determination of the spreads of the cost of borrowing indicators using these alternative specifications. To be more precise, we tried the model in the differenced version, where all variables appeared in first differences. We also checked the model with the lagged dependent variable included as a regressor and finally, we ran our model using different specifications of instruments. All the above variations showed in most cases results like the ones we report here.

\section{Data}

As mentioned earlier, as a measure of banking market interest rates we use the 
recently produced ECB's cost of borrowing indicators (ECB, 2013). More specifically, we use a monthly panel of the ECB's long-term and short-term cost of borrowing indices, related to new loans to business and households, for the period January 2003-June 2015. These newly constructed indices represent a more reliable indicator of the prevailing bank lending rates in each country, compared to the older harmonized statistics on individual market segment interest rates. We use data for Belgium, France, Netherlands, Ireland, Italy, Greece, Portugal and Spain.

Among the improved characteristics of these indices, are the inclusion of interest rates on overdrafts as a form of short-term lending, and the characterization of the floating rate long term loans to NFIs as short-term borrowing (since it can be viewed in the context of refinancing of firms, ECB, 2013). As all these indicators are composed by weighting averages of individual loan rates, a weighting scheme must be applied.

According to ECB (2013), weighting each individual interest rate based on outstanding amounts of loans captures the financing structure of the economy more accurately. However, data on balance sheets are available on a different time pattern than data on interest rates, thus making the weighting procedure not so reliable. On the other hand, an aggregation based on new business volumes provides a better measure of the impact of the marginal cost of a new loan on the overall financing cost structure. Weighting averages based on new business loans however might become more volatile than the underlying interest rates because of the volatile nature of these volumes. This is the reason a moving average of two years is used concerning the amount of new business volumes used for weighting (ECB, 2013).

A drawback of choosing the use of the cost of borrowing indicators rather than individual rates, is that ECB publishes only highly aggregated indices for the cost of borrowing of a) total short-term bank lending, b) total long-term bank lending, c) total lending to firms, and d) total lending to households. Here we focus on the first two indicators, namely the cost of borrowing for short-term and the long-term lending.

For capturing country risk differentials, we use the spread of each country 10-year government bond yield vis-a-vis Germany, (ECB data on bond yields). For calculating inflation rates, we use the annual growth rate of the CPI index provided by the ECB for each country. For GDP growth rates, we obtained quarterly data for GDP growth produced by the OECD. Since only quarterly growth data is available for the countries in question, we used a cubic spline interpolation to produce monthly growth rate series.

As our purpose is to assess whether there are significant associations between the dispersion of the cost of borrowing indicators and the individual country characteristics, all variables are in the form of spreads vis-a-vis the corresponding German value for the same month. Another reason for considering differentials 
rather than levels, is to control for potential common trends in the series of individual countries.

\section{Estimation Results}

\subsection{Estimation of the model for the whole period}

Tables 1 and 2 show the estimated parameters of the system of equations (2) and (3), namely the estimated coefficients of the bond yield spreads, the growth rate differentials and inflation differentials for each individual country. Table 1 shows the model is estimation results for the cost of borrowing on short-term bank lending, while Table 2 shows the estimation results in the case of long-term lending. In the column next to estimated coefficients, the Newey and West heteroskedasticity and autocorrelation corrected standard errors are shown, based on the Bartlett kernel. In the last column of each table the probability value is reported. Finally, at the end of each country's results we report the critical value of the Hansen's J statistic for overidentifying restrictions and its probability.

As described earlier, the number of instruments used (and so the moment equations provided), were more than the number of parameters in the model. Had we used the same number of moments as the number of parameters, we could still be able to produce an estimation of the model. Thus, independently of the instruments used, the parameter estimates should not differ too much regardless of which moment conditions the estimator uses to estimate the parameters. The Hansen's J statistic used here, is a Chi square test, checking the hypothesis that the parameters do not change that much when a different subset of instruments is used. Hence, the test can be perceived to evaluate the validity of our instruments, providing possible signs of model misspecification. As can be seen in table 1, the probability value of this test is greater than 0.05 in all cases, allowing us not to reject the null hypothesis and to conclude that the model is not mis specified.

In general, for each country the bank interest rate differential is expected to be positively related to country's sovereign bond spread, to its growth rate differential and to its inflation rate differential. Increasing sovereign bond spread might reflect increasing country risk premia, a development that might increase interest rates of all kinds of lending in the country. On the other hand, growth rate and inflation rate differentials for a country could signify faster growing aggregate demand relative to the benchmark country and thus higher demand for loans and higher interest rates. Moreover, a higher inflation rate in a country might lead to higher interest rates because of the Fisher effect. The results of Table 1 and 2, suggest that in many cases there is no significant systematic relation between cost of borrowing spreads and the spreads between bond yields, growth rates and inflation rates. Thus, the general picture from the estimation using data for the whole period under examination is that the cost of borrowing spreads for Belgium, Italy and Netherlands and Greece are not significantly related with the sovereign risk spreads, or divergent economic 
conditions. For Greece, however, there is one exception since there is significant contribution of the inflation differential in explaining the long-term cost of borrowing spreads.

Table 1. Estimated parameters of the system for short-term bank lending for the whole period (2003-15)

\begin{tabular}{|c|c|c|c|c|}
\hline & & Coefficient & $\begin{array}{c}\text { Std. Error } \\
\text { (HAC) }\end{array}$ & P-value \\
\hline \multirow[t]{5}{*}{ Belgium } & Const. & 0.01 & 0.02 & 0.70 \\
\hline & Bonds & 0.19 & 0.22 & 0.38 \\
\hline & Growth & 0.01 & 0.02 & 0.77 \\
\hline & Inflation & 0.02 & 0.05 & 0.73 \\
\hline & & Hansen's J: & 4.18 & 0.24 \\
\hline \multirow[t]{5}{*}{ Spain } & Const. & 0.01 & 0.05 & 0.80 \\
\hline & Bonds & 0.54 & 0.10 & 0.00 \\
\hline & Growth & 0.07 & 0.02 & 0.00 \\
\hline & Inflation & -0.04 & 0.11 & 0.69 \\
\hline & & Hansen's J: & 3.55 & 0.31 \\
\hline \multirow[t]{5}{*}{ France } & Const. & 0.02 & 0.05 & 0.75 \\
\hline & Bonds & 1.42 & 0.54 & 0.01 \\
\hline & Growth & -0.07 & 0.02 & 0.00 \\
\hline & Inflation & -0.12 & 0.05 & 0.02 \\
\hline & & Hansen's J: & 1.90 & 0.59 \\
\hline \multirow[t]{5}{*}{ Italy } & Const. & 0.00 & 0.04 & 0.96 \\
\hline & Bonds & 0.22 & 0.17 & 0.20 \\
\hline & Growth & -0.01 & 0.06 & 0.89 \\
\hline & Inflation & -0.03 & 0.08 & 0.70 \\
\hline & & Hansen's J: & 7.16 & 0.07 \\
\hline \multirow[t]{5}{*}{ Netherlands } & Const. & 0.01 & 0.03 & 0.65 \\
\hline & Bonds & 0.18 & 1.28 & 0.89 \\
\hline & Growth & 0.02 & 0.10 & 0.83 \\
\hline & Inflation & -0.23 & 0.56 & 0.68 \\
\hline & & Hansen's J: & 1.74 & 0.63 \\
\hline \multirow[t]{5}{*}{ Portugal } & Const. & 0.01 & 0.06 & 0.83 \\
\hline & Bonds & 0.35 & 0.11 & 0.00 \\
\hline & Growth & 0.03 & 0.05 & 0.60 \\
\hline & Inflation & -0.25 & 0.09 & 0.01 \\
\hline & & Hansen's J: & 7.60 & 0.06 \\
\hline \multirow[t]{3}{*}{ Greece } & Const. & 0.01 & 0.04 & 0.89 \\
\hline & Bonds & 0.05 & 0.03 & 0.12 \\
\hline & Growth & -0.03 & 0.02 & 0.12 \\
\hline
\end{tabular}


Country Risk on the Bank Borrowing Cost Dispersion Within the Euro Area during the Financial and Debt Crises

\begin{tabular}{ccccc}
\hline \multirow{3}{*}{ Ireland } & Inflation & -0.07 & 0.06 & 0.21 \\
& & Hansen's $J$ & 4.07 & 0.25 \\
& Const. & 0.01 & 0.04 & 0.85 \\
& Bonds & 0.11 & 0.11 & 0.35 \\
& Growth & -0.01 & 0.01 & 0.45 \\
& Inflation & $\mathbf{0 . 0 7}$ & 0.03 & 0.01 \\
& & Hansen's J: & 5.01 & 0.17 \\
\hline
\end{tabular}

Notes: Bold numbers show significance at the 5\% confidence level.

Table 2. Estimated parameters of the system for long-term bank lending the whole period (2003-15)

\begin{tabular}{|c|c|c|c|c|}
\hline & & Coefficient & $\begin{array}{l}\text { Std. Error } \\
\text { (HAC) }\end{array}$ & P-value \\
\hline \multirow[t]{5}{*}{ Belgium } & Const. & 0.05 & 0.07 & 0.50 \\
\hline & Bonds & 0.07 & 0.46 & 0.88 \\
\hline & Growth & 0.01 & 0.04 & 0.81 \\
\hline & Inflation & -0.03 & 0.09 & 0.70 \\
\hline & & Hansen's J: & 3.27 & 0.35 \\
\hline \multirow[t]{5}{*}{ Spain } & Const. & 0.07 & 0.09 & 0.44 \\
\hline & Bonds & 0.97 & 0.43 & 0.03 \\
\hline & Growth & 0.10 & 0.06 & 0.10 \\
\hline & Inflation & 0.04 & 0.22 & 0.85 \\
\hline & & Hansen's $J$ : & 1.43 & 0.70 \\
\hline \multirow[t]{5}{*}{ France } & Const. & 0.03 & 0.05 & 0.53 \\
\hline & Bonds & 2.13 & 0.79 & 0.01 \\
\hline & Growth & 0.00 & 0.03 & 0.91 \\
\hline & Inflation & 0.01 & 0.05 & 0.83 \\
\hline & & Hansen's J: & 4.73 & 0.19 \\
\hline \multirow[t]{5}{*}{ Italy } & Const. & 0.01 & 0.06 & 0.93 \\
\hline & Bonds & 0.10 & 0.29 & 0.73 \\
\hline & Growth & -0.15 & 0.09 & 0.12 \\
\hline & Inflation & -0.01 & 0.13 & 0.93 \\
\hline & & Hansen's J: & 5.63 & 0.13 \\
\hline \multirow[t]{5}{*}{ Netherlands } & Const. & -0.05 & 0.25 & 0.85 \\
\hline & Bonds & 4.64 & 7.41 & 0.53 \\
\hline & Growth & 0.36 & 0.81 & 0.66 \\
\hline & Inflation & -2.02 & 3.91 & 0.61 \\
\hline & & Hansen's $J$ : & 3.03 & 0.39 \\
\hline \multirow[t]{3}{*}{ Portugal } & Const. & -0.05 & 0.17 & 0.75 \\
\hline & Bonds & -0.53 & 0.24 & 0.03 \\
\hline & Growth & -0.43 & 0.15 & 0.00 \\
\hline
\end{tabular}




\begin{tabular}{ccccc}
\hline \multirow{3}{*}{ Greece } & Inflation & -0.13 & 0.25 & 0.60 \\
& & Hansen's $J:$ & 2.69 & 0.44 \\
& Const. & 0.08 & 0.08 & 0.31 \\
& Bonds & -0.03 & 0.05 & 0.61 \\
& Growth & -0.02 & 0.04 & 0.62 \\
Ireland & Inflation & $\mathbf{0 . 2 2}$ & 0.11 & 0.04 \\
& & Hansen's J: & 4.08 & 0.25 \\
& Const. & -0.05 & 0.14 & 0.71 \\
& Bonds & $\mathbf{- 0 . 5 3}$ & 0.26 & 0.04 \\
& Growth & 0.05 & 0.04 & 0.23 \\
& Inflation & $\mathbf{0 . 3 8}$ & 0.12 & 0.00 \\
& & Hansen's J: & 2.06 & 0.56 \\
\hline
\end{tabular}

Notes: Bold numbers show significance at the 5\% confidence level.

On the other hand, however, a significant positive impact of the bond yield spreads on the cost of borrowing differentials (for the whole period examined) can be observed in the cases of France, Spain and Portugal, although in for Portugal the relevant coefficient shows the expected sign only in the case of short-term lending. As shown in Table 2, in the cases of the long-term cost of borrowing in Portugal and Ireland a significant negative relationship between bond yield spread and cost of borrowing differential is observed.

Thus, the conclusion reached here is that the hypothesis that country risk premia have a systematic positive impact on the cost of borrowing dispersion cannot be rejected, only for four out of the eight-euro area members considered. On the other hand, divergent economic conditions as represented by differences in inflation and growth rates appear to be significant determinants of the cost of borrowing spreads, mainly for peripheral countries (France, Spain, Ireland, Portugal and Greece).

\subsection{Rolling Estimation results}

Thus, the general conclusion from the estimation of the model for the whole period is that there is only sporadic evidence supporting a positive impact of country risk premia and divergent economic conditions on bank interest rate dispersion. However, the importance of such a relationship could vary through time. For example, someone might expect a stronger association between bank interest rate spreads and country risk premia during periods of financial distress. In order to evaluate the through time evolution of the relationship between the cost of borrowing dispersion and its determinants described earlier, we perform a rolling estimation of the system of equations (2) and (3). Here, due to limited space, we only present the evolution of the estimated coefficient of the bond yield spread (the $\beta$ of equation (2)), together with its $95 \%$ confidence interval, constructed using the HAC Newey-West standard errors. At each point in time, the coefficient reported is calculated for the sub-period of the previous 48 months. For example, the estimated 
coefficient reported for January 2007 is derived by using the sub-sample from January 2003 to December 2006, the February 2007 coefficient corresponds to the sample from February 2003 to January 2007 etc.

Figures 1 and 2 in the Appendix show the evolution of these coefficients for the eight-euro area members both for short-term and long-term costs of borrowing. We firstly discuss the results in relation to the short-term cost of borrowing spreads. A close examination of the country graphs leads to the following conclusions: first, the general picture is that the impact of the sovereign risk is not significant determinant for the cost of borrowing dispersion, since for most of the period and most of the countries, the coefficient of the bond yield spreads appears to be non-significant. Second, the impact of bond yield spreads on cost of borrowing differentials becomes significant for all the countries for some sub-periods in the post 2007 crisis era. This significance is stronger and more persistent for the countries that were severely affected by both the world financial crisis and the euro area debt related crisis (eg. peripheral countries such as Portugal, Italy, Spain); however, for the heavily affected by the debt crisis Greece this result does not hold. On the other hand, in the case of France the coefficient has been persistently significant for most of the crisis period. Finally, for the 2014-15 period, a period of less financial turbulence, the impact of the sovereign risk spreads has become insignificant for all the countries, except for Portugal.

On the other hand, the results are not so similar when examining the evolution of the coefficients referring to the long-term cost of borrowing differentials. As with the previous case, the general picture is that the long-term cost of borrowing spreads is not significantly related to sovereign risk spread in the majority of the cases. However, it is shown that the significance of such relationship has not been upgraded during the period of financial turbulence in most countries with exception of France and Italy. Surprisingly, sovereign spreads do not seem to be significant determinants of the cost of borrowing differentials in long term lending for the euro area peripheral countries, even during the period of euro area debt crisis. This outcome has positive implications for the single monetary policy and the financial integration process in the euro area, since it suggests that the long-term lending rates, being important for investment and firm expansion, are not closely related to sovereign risk spreads.

\section{Conclusions}

The main aim of this study is to empirically evaluate the association between the dispersion of the bank borrowing cost for firms and households and the government bond yield spreads of individual countries within the euro area. In order to better capture the effects of the sovereign risk on the cost of borrowing dispersion, we used additional explanatory variables for the cost of borrowing spreads, namely inflation rate and growth rate differentials. We empirically investigate this relationship with the use of a model of system equations and the three-stage least-squares (3SLS) 
estimator.

Our results have led to an overall conclusion suggesting that there is not any systematic and persistent relationship between sovereign risks and cost of borrowing dispersion within the euro area. A significant relationship between these variables can only be observed for the turbulent periods of the 2007-9 world financial crisis and the subsequent euro area debt crisis, and for specific member states that mostly affected by the crises. Moreover, the increasing importance of sovereign spreads in determining the cost of borrowing differentials during the crisis periods is less evident in the case of bank long-term lending compared to bank short-term lending.

The evidence presented here have positive implications for the implementation of the single monetary policy since country specific sovereign risk premia do not seem to assert a permanent impact on banking market interest rates. Consequently, the increased dispersion of the cost of bank borrowing observed in the euro area during the current financial turbulence cannot be explained by increasing sovereign risks. Divergent economic conditions and, more importantly, structural differences of the banking sector and individual characteristics of the firms and households across countries might offer a better explanation for the limited cost of borrowing convergence in the euro area.

\section{References:}

Acharya, V.V., Steffen, S.2013. The Greatest Carry Trade Ever? Understanding Eurozone Bank Risks. CEPR Discussion Papers 9432.

Affinito, M., Farabullini, F. 2006. An empirical analysis of national differences in the retail bank interest rates of the euro area. Economic working papers, 589, Bank of Italy.

Allegret, J.P., Raymond, H. and Rharrabti, H. 2016. The Impact of the Eurozone Crisis on European Banks Stocks, Contagion or Interdependence. European Research Studies Journal, 19(1), 129-147.

Barro, R.J., Sala-i-Martin, X. 1992. Convergence. Scholarly Articles 3451299, Harvard University Department of Economics.

Becker, B., Ivashina, V. 2014. Cyclicality of Credit Supply: Firm Level Evidence. Journal of Monetary Economics, 62, 76-93.

Becker, B., Ivashina, V. 2014. Financial Repression in the European Sovereign Debt Crisis. Swedish House of Finance, Research Paper No. 14-13, Paris, Finance Meeting EUROFIDAI - AFFI Paper.

Blot, C., Labondance, F. 2013. Business lending rate pass-through in the Eurozone: monetary policy transmission before and after the financial crash. Economics Bulletin, 33(2), 973-985.

Boldeanu, T.F., Tache, I. 2016. The Financial System of the EU and the Capital Markets Union. European Research Studies Journal, 19(1), 60-70.

Cabral, I., Dierick, F., Vesala, J.M. 2002. Banking Integration in the Euro Area. ECB Working Paper No. 6.

Chronis, P., Zombanakis, G. 2016. An Evaluation of Policies for Fiscal and External Sustainability during the Recent Greek Economic Crisis. European Research Studies Journal, 19(1), 34-44. 
Duguleana, L., Duguleana, C. 2016. Structural Aspects of the European Union Economy. European Research Studies Journal, 19(1), 93-128.

European Central Bank. 2013. Assessing the retail bank interest rate pass-through in the euro area at times of financial fragmentation. Monthly Bulletin, August.

Furceri, D. 2005. B and r-convergence: A mathematical relation of causality. Economic Papers, 89(2).

Gennaioli, N., Martin, A., Rossi, S. 2014. Sovereign Default, Domestic Banks, and Financial Institutions. Journal of Finance, 69(2), 819-866.

Greene, W. 2000. Econometric Analysis. Upper Saddle River, NJ., Prentice Hall.

Hodrick, R.J., Prescott, C.E. 1997. Postwar U.S. business cycles: An empirical investigation. Journal of Money, Credit and Banking, 29, 1-16.

Illes, A., Lombardi, M.J. 2013. Interest rate pass-through since the financial crisis. Bank for International Settlements, September.

Kleimeier, S., Sander H. 2002. Consumer Credit Rates in the Eurozone: Evidence on the Emergence on a Single Retail Banking Market. ECRI Research Report No. 2.

Neri, S. 2013. The impact of the sovereign debt crisis on bank lending rates in the euro area. Occasional Papers, 170, Bank of Italy, Economic Research and International Relations Area.

Paries, M.D., Moccero, D., Krylova, E., Marchini, C. 2014. The retail bank interest rate passthrough: The case of the euro area during the Financial and Sovereign Debt Crisis. ECB Occasional Paper No. 155.

Thalassinos, I.E., Pintea, M., Raţiu, I.P. 2015a. The Recent Financial Crisis and Its Impact on the Performance Indicators of Selected Countries during the Crisis Period: A Reply. International Journal of Economics and Business Administration, 3(1), 3-20.

Thalassinos, I.E., Stamatopoulos, D.T. and Thalassinos, E.P. 2015b. The European Sovereign Debt Crisis and the Role of Credit Swaps. Chapter book in The WSPC Handbook of Futures Markets (eds) W. T. Ziemba and A.G. Malliaris, in memory of Late Milton Miller (Nobel 1990) World Scientific Handbook in Financial Economic Series Vol. 5, Chapter 20, pp. 605-639, ISBN: 978-981-4566-91-9, (doi: 10.1142/9789814566926_0020).

Vajanne, L. 2007. Integration in euro area retail banking markets convergence of credit interest rates. Research Discussion Papers 27/2007, Bank of Finland.

Zellner, A., Theil, H. 1962. Three stage least squares: Simultaneous estimate of simultaneous equations. Econometrica, 29, 54-78. 


\section{Appendix:}

Figure 1. The estimated coefficient of bond yield spreads and its confidence intervals from the rolling system GMM regressions (equation 1): The case of short-term cost of borrowing
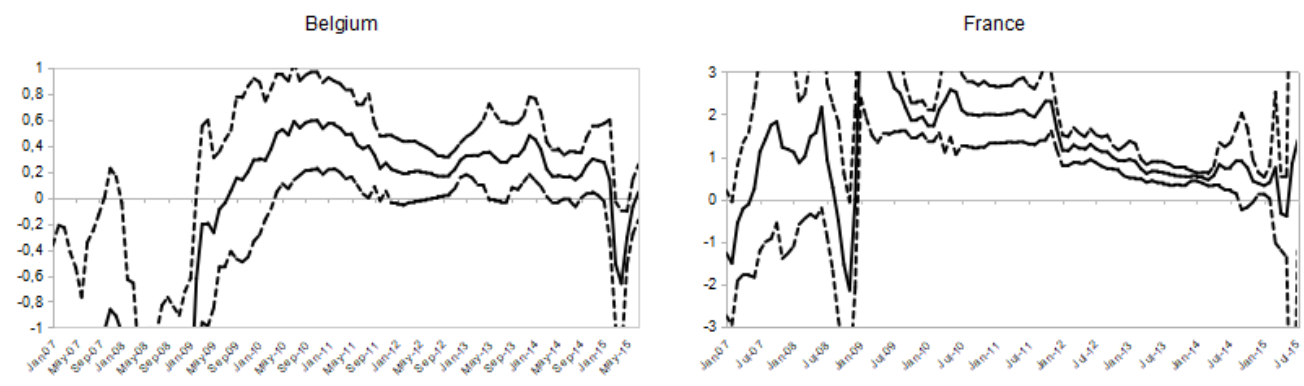

Greece

Ireland
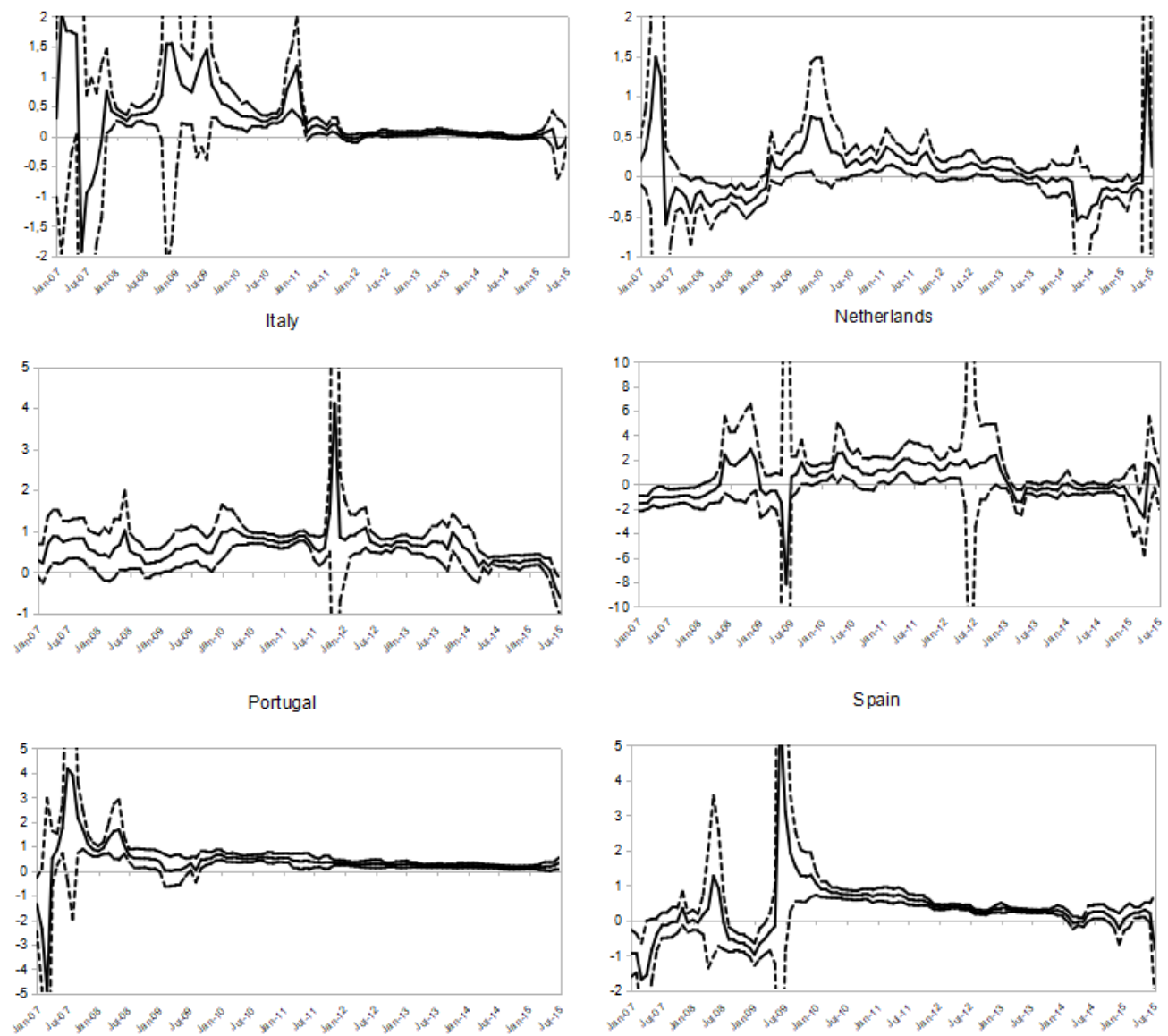
Figure 2. The estimated coefficient of bond yield spreads and its confidence intervals from the rolling system GMM regressions (equation 1): The case of longterm cost of borrowing
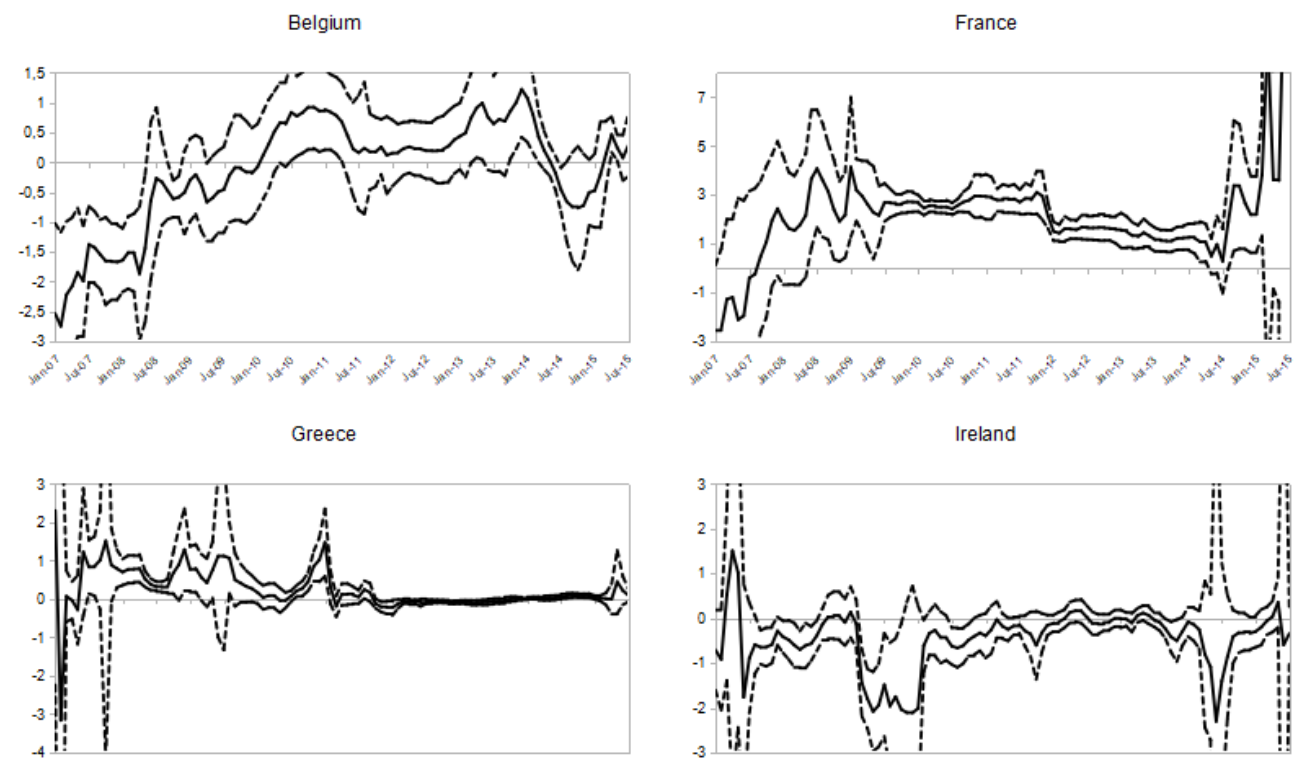

Italy
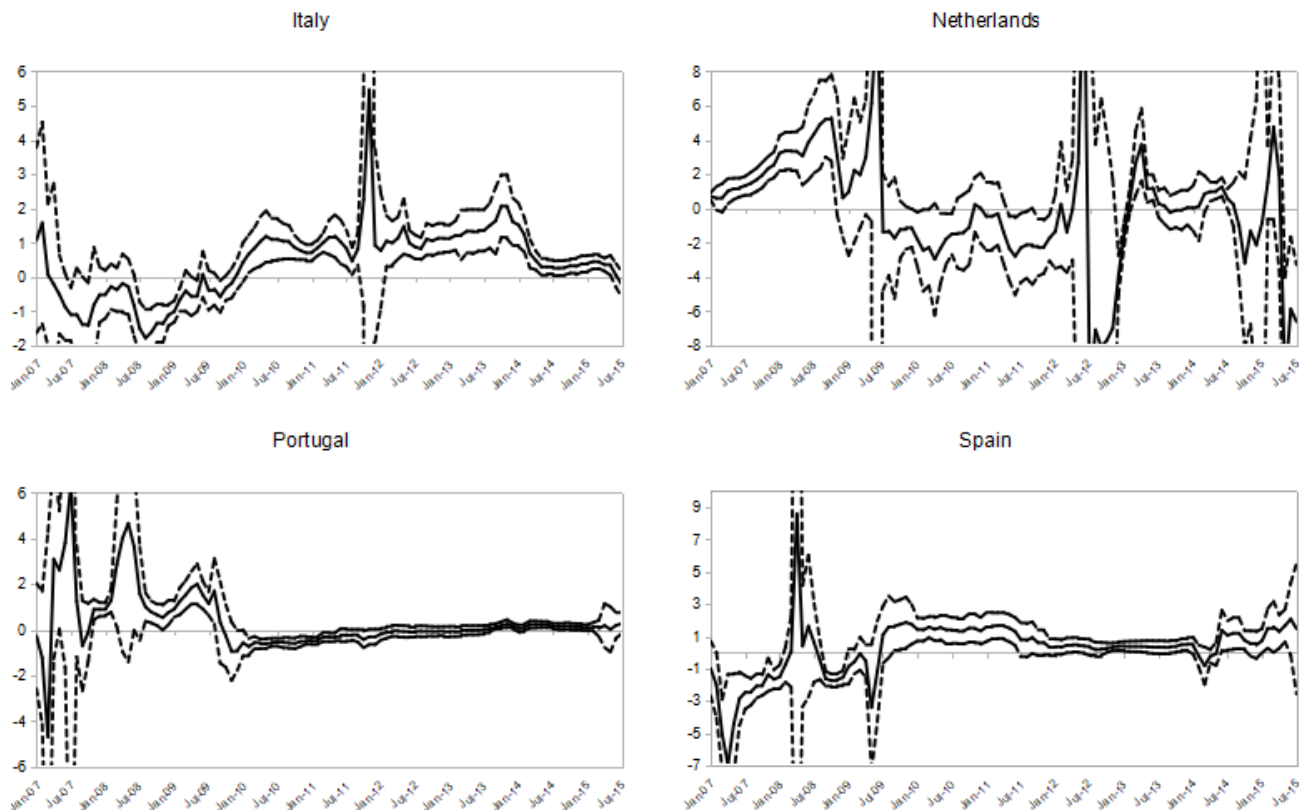